\title{
CHALLENGING ASSUMPTIONS
}

\section{Silences and Double Binds: Why the Theories of John Dewey and Paulo Freire Cannot Contribute to Revitalizing the Commons}

\author{
C. A. Bowers
}

The growing awareness that the rate and nature of change in the world's cultures is not sustainable by the Earth's ecosystems now makes it possible to ask questions about certain ideas of John Dewey and Paulo Freire that were overlooked by earlier followers and critics. Indeed, a case can be made that the recent revival of interest in Dewey is partly due to the assumption that he has been overlooked as an early environmental thinker. ${ }^{1}$ A recent work by Moacir Gadotti, the Director of the Instituto Paulo Freire in Brazil, makes a similar attempt to represent Freire as a leading environmental educator. ${ }^{2}$ However, both Dewey and Gadotti (and by extension, Freire) fail to give sufficient value to differences in cultural knowledge systems. Instead, they postulate that education can create a planetary consciousness only by not degenerating into a process of cultural transmission. This was integral to Dewey's philosophy of education and became a hallmark of Freire's argument for an emancipatory pedagogy.

These efforts raise the basic question of whether the cultural assumptions that both Dewey and Freire took for granted doom their efforts to failure from an environmental or, to be more exact, an ecological perspective. I will argue that in spite of their concern with social justice, Dewey and Freire shared a number of assumptions with today's proponents of globalizing the industrial/consumer-based culture which drives planetary ecological breakdown. I begin by summarizing four major trends that put our collective future at risk. This summary is intended to serve as a reference point for assessing whether the pro-environmental interpretations of the core ideas of Dewey and Freire can turn them into sources of resistance to these destructive trends.

\footnotetext{
${ }^{1}$ Andrew Light and Eric Katz (eds.), Environmental Pragmatism (New York: Routledge, 1996).

${ }^{2}$ Moacir Gadotti, Pedagogy of the Earth and Culture of Sustainability (Sao Paulo: Instituto Paulo Freire, 2002), pp. $1-11$.
} 


\section{The Ecological Crisis}

The ecological crisis has many elements: the depletion of fisheries beyond their capacity to renew themselves; the increasing shortage of potable water; global warming that is changing habits and threatening species; loss of topsoil now estimated at 33 percent on a worldwide scale; the increasing amount of toxins in the environment - including the oceans. In short, the ability of nature to sustain the life of humans and other species is being rapidly diminished.

\section{Globalization of the West's Technological, Consumer-dependent Culture}

The expansion of the world's population is accompanied by the globalization of the money-based economy, with greater dependence upon consumerism and the adoption of new technologies - including technologies that contribute to outsourcing to regions where workers can be more easily exploited. These trends are broadly under the aegis of a Western capitalist culture that undermines what remains of the intergenerational knowledge, both here and in other cultures, which represents alternatives to a consumerist lifestyle. These trends are enforced by international institutions such as the World Bank, the International Monetary Fund, and the World Trade Organization - all of which are based on neoliberal ideas and values that represent all aspects of human activity, as well as the natural environment, as exploitable markets.

\section{Loss of Cultural/linguistic Diversity}

The forces that promote consumerism and the Western form of consciousnessthe media, computers, corporate advertising, Western universities, etc. - also contribute to the loss of linguistic diversity. A large number of the approximately 6,000 languages still spoken today (some by only a few members of the culture) will disappear in the next few decades. The loss of these languages will contribute to the further loss of species, as it is now understood by some linguists that these languages encode the knowledge of the renewing cycle of plants and animals within the bioregion where they are spoken. ${ }^{3}$ Within these cultures, language carries forward the intergenerational knowledge of how to meet daily needs without degrading the ecosystems they depend upon, and thus is inextricably related to how a culture impacts the local environment. However, languages based on Western assumptions represent the rational process as being able to overcome the adverse impact of humans on the environment, and thus distort how to understand a sustainable relationship between cultural practices and the sustaining capacity of the environment.

\footnotetext{
${ }^{3}$ Daniel Nettle and Suzanne Romaine, Vanishing Voices: The Extinction of the World's Languages (New York: Oxford University Press, 2000) pp. 60-68. Peter Muhlhausler, Linguistic Ecology: Language Change and Linguistic Imperialism in the Pacific Region, (London: Routledge, 1996).
} 


\section{Revitalization of the Cultural and Environmental Commons Represents Sites of Resistance to the Forces of Globalization}

While the enclosure of the environmental commons began well before the Industrial Revolution, both the cultural and environmental commons are now being monetized and integrated into industrial/consumer-oriented culture on a global scale. Every aspect of the cultural and environmental commons is now subject to being appropriated as private or corporate property, from the intergenerational knowledge and skills that enabled people to live less consumer-dependent lives to the gene lines of humans, plants, and animals. Even the airwaves and the new commons of cyberspace are being monetized. Resistance to the further enclosure of the commons can be found in many Third World cultures, including those of Mexico, Peru, Bolivia, and India. In addition, individuals, groups, and institutions in so-called developed countries are resisting the further enclosure of what were previously public lands. Resistance in these countries is also taking the form of living lives of voluntary simplicity, recovering the tradition of "slow food," and renewing networks of mutual support. These groups are attempting to conserve traditions that enable people to live less monetary-dependent and environmentally destructive lives, and their mindful conservatism stands in sharp contrast to what Jorge Ishizawa refers to as the "colonizing gaze" of the neoliberals that equate progress with the economic exploitation of the commons. ${ }^{4}$

While the above summary does not adequately identify the social justice issues in some of the world's commons, it nevertheless foregrounds the key ideas and issues that will be used here to assess whether the ideas of John Dewey and Paulo Freire are complicit in promoting global culture that can expand only as it further encloses the world's cultural and environmental commons. The task is to assess where these two theorists stand on the key issues summarized above, which may be further condensed into a portrait of the dominant culture as follows: viewing change as linear and progressive in nature; promoting the assumptions and ways of thinking that gave conceptual direction and moral legitimacy to the development of the Industrial Revolution that is now in its digital phase of development-while reproducing the assumptions of classical liberal social theorists; failing to recognize that cultural/linguistic diversity contributes to conserving species diversity and sustainable habitats; and failing to recognize the nature and importance of the cultural commons as an alternative to the moneydependent lives required by the industrial/capitalist culture. Further, we need to scrutinize the ideas of Dewey and Freire with respect to their failure to recognize that critical inquiry is as important to determining what needs to be conserved as it is to determining what needs to be changed.

${ }^{4}$ Personal conversation when I was in Peru. 


\section{Silence of Dewey and Freire About the Nature of the Ecological Crisis}

At first glance it may appear unfair to criticize Dewey for ignoring the ecological crisis since scientists and elements of the public did not recognize that the sustaining capacity of natural systems was being undermined until well after his death. Yet the fact remains that the essentials of the ecological crisis as we now understand it were well underway during Dewey's formative years. The method of intelligence, he tells us over and over again, is initiated by problematic situations - that is, when there is doubt as to how to proceed. There was a great deal of ecologically relevant doubting going on during Dewey's active period, which somehow eluded him. Clear-cutting of the forests across the United States was in full swing during his years in Chicago and New York - but he gave no evidence of concern about this. The killing off of millions of bison, which was given wide press coverage, also escaped his attention as a problematic situation. The writings of Henry David Thoreau and John Muir also appear to have escaped his attention, as well as the conservation arguments of Theodore Roosevelt and Gifford Pinchot.

It should be pointed out as well that Dewey, the apostle of democratic decision-making, also ignored the killing off of indigenous people in order to appropriate their land which, along with the cultural subjugation of those who survived can arguably be called genocide. As Dewey was born in 1859, his early years were spent in the context of continuous warfare against native people, particularly in the West. The campaign against the Sioux lasted from 1854 to 1890, against the Southern Plains indigenous cultures from 1860 to 1879 , and against the Nez Perce in 1877, and lasted against the Apache from 1861 to 1900. The best explanation for Dewey's silence about these morally problematic situations is that he shared the racist attitudes of his era-which was reflected in his references to how the lives of "savages" (his word) were governed by habits rather than the use of intelligence.

As many of his current followers are likely to react negatively to the criticism that Dewey shared the racist attitudes of his times, I shall provide a quotation from Democracy and Education that reveals a surprising degree of ignorance and prejudice from one of the country's leading philosophers. Here is how Dewey explains the "savage's" lack of intelligence:

Savages react to a flaming comet as they are accustomed to react to other events that threaten the security of their life. Since they try to frighten wild animals or their enemies by shrieks, beating of gongs, brandishing weapons, etc., they use the same methods to scare away the comet. To us, the use of the method is plainly absurd - so absurd that we fail to note that savages are simply falling back upon habit in a way which exhibits its limitations. ${ }^{5}$

${ }^{5}$ John Dewey, Democracy and Education (New York: Macmillan, 1916), p. 396. 
Dewey's way of representing habits, or what in a cultural context can be understood as traditions, as the opposite of what he calls the method of intelligence exemplifies a basic misconception, with broader implications that will be examined later.

Paulo Freire, a more contemporary theorist with an active following around the world, also ignored the ecological crisis. His most influential book, Pedagogy of the Oppressed, ${ }^{6}$ as well as his other books published in the 1970s and 80s, are totally silent on the implications of the ecological crisis for educational reform. The closest he comes to acknowledging the crisis is a generalized reference to environmental problems. But this did not lead to any rethinking of his main concern, which was to explain how the practice of conscientizacao (awaking of critical awareness) enables people to realize their fullest potential as human beings. Moacir Gadotti, as mentioned earlier, claims that Freire began to write on the need for an "ecopedagogy" just before his death. At an international conference held in Toronto in 2003, Gadotti predicted that when Freire's initial thoughts on the nature of an ecopedagogy are published, he will be recognized as a leading environmental thinker. In the meantime, Gadotti's writings were to be understood as an elaboration on Freire's unpublished insights.

While we currently only have access to Gadotti's elaborations on Freire's last thoughts on the educational implications of the ecological crisis, it is important to recognize that Gadotti's proposals are consistent with Freire's two main ideas: that there is only one legitimate approach to knowledge (critical reflection) and that knowledge should not be passed on from generation to generation, which Freire labeled as the banking approach to learning. To quote Gadotti: "Education, then, would not be as Emile Durkheim explained, the transmission of culture 'from one generation to the next,' but the grand journey of each individual in his interior universe and the universe that surrounds him." ${ }^{.7}$ Gadotti's recommendation that a planetary consciousness should replace the current diversity of the world's cultures is consistent with Freire's idea that there is only one approach to knowledge. This profoundly questionable recommendation is justified on the following grounds: "Globalization in itself does not pose a problem, since it constitutes an unprecedented process of advancement in the history of humankind."

Gadotti's sweeping generalization that knowledge should not be passed from one generation to the next is equally questionable. Given that being born into a culture and learning its linguistic and communicative patterns is an inescapable aspect of human existence as well as cultural transmission, Gadotti's recommendation seems extremely naïve as well as problematic. Yet, Gadotti is accurately representing Freire's

\footnotetext{
${ }^{6}$ Paulo Freire, Pedagogy of the Oppressed, trans. Myra Bergman Ramos (New York: Continuum [Seabury], 2000). This, the thirtieth anniversary edition, states on the jacket that 750,000 copies have been sold.

${ }^{7}$ Gadotti, op. cit., p. 8.

${ }^{8}$ Ibid.
} 
hard-and-fast distinction between what he identifies as the de-humanizing banking approach to learning and the humanizing nature of critical reflection. As Freire put it:

\begin{abstract}
Human existence cannot be silent, nor can it be nourished by false words, but only by true words, with which men transform the world. To exist humanly, is to name the World, to change it. Once named, the world in its turn reappears to the namers as a problem and requires of them a new naming. Men are not built in silence, but in word, in work, in action-reflection. But while to say the true word - which is work, which is praxis - is to transform the world, saying that word is not the privilege of some few men, but the right of every man. Consequently, no one can say a true word alone - nor can he say it for another, in a prescriptive act which robs others of their words. ${ }^{9}$
\end{abstract}

Freire goes on to discuss the importance of dialogue as a way of avoiding any form of domination, but he ignores the problem of whether it is totally possible to avoid what he refers to as "dehumanizing aggression." The important point here is that each individual and, by extension, each generation, is expected to arrive at her/ his own understanding - including what changes are occurring in the environment and what the implications are for "transforming the world." Even if individuals were to arrive at an understanding of the extent of the ecological crisis, this knowledge could not be passed on to the next generation without it becoming an example of dehumanizing aggression - to recall Freire's words.

\title{
The Problem of Reconciling the One-True-Approach to Knowledge of Dewey and Freire With the Need to Conserve the World's Cultural and Linguistic Diversity
}

It is surprising that the ethnocentrism that characterizes the thinking of both Dewey and Freire has gone unnoticed by their followers. Perhaps this is because they are rooted in the same ethnocentrism, and therefore find self-recognition difficult. It is also surprising that both Dewey and Freire have been acclaimed as promoters of democracy as well as emancipation from past sources of injustice, given these core assumptions. This is to overlook Dewey's argument, repeated over and over, that what he calls the method of intelligence (experimental inquiry) is the only valid approach to knowledge - knowledge which is always to be held provisionally. Dewey's ethnocentrism can be seen in the book, Reconstruction in Philosophy, based on lectures he presented in 1919 at the Imperial University in Japan. Although he must have been aware that his hosts and the audience attending his lectures lived in accordance with profoundly different traditions and had a very high level of cultural achievement, the only aspect of their culture that he mentions in the Prefatory Note

${ }^{9}$ Ibid., p. 77. 
to the book Reconstruction in Philosophy is their extreme courtesy. ${ }^{10}$ The main message he presented to his Japanese audience was that change is the dominant reality, that the use of the experimental method of inquiry is the only way to control the direction of change and thus to experience progress, and that cultures that do not adopt this new scientifically based way of thinking would remain locked in a spectator approach to knowledge. He further warned that without the method of experimental inquiry for reconstructing experience, there would be no chance of achieving a democratic society, nor of realizing the "industrialization (that) is the direct fruit of the growth of the experimental method of knowing."11

Dewey's claim that there is only one approach to knowledge is given ontological status rather than being recognized as the privileged way of thinking of the elites who were then building an industrial-based culture in the West. This is basically undemocratic. The contradiction inherent in associating the worldwide promotion of Dewey's experimental approach to knowledge and values with the spreading of democracy, when in reality it would undermine the diversity of the world's cultures, has also gone unnoticed by his followers. The universalizing of Dewey's ideas represents a form of cultural colonization that undermines what many cultures have accumulated as a fund of intergenerational knowledge about how to live within the limits of the local ecosystems. ${ }^{12}$

Freire's rejection of all forms of cultural transmission as impeding the right of each individual to rename the world of the previous generation has also become the basis for justifying, in the name of emancipation and freedom, the colonization of what are considered less evolved cultures. Today, Freire's idea that each individual is to name the world anew is the basis, along with the ideas of Dewey and Piaget, of what is now referred to as a constructivist approach to learning. The idea that each student is to construct her/his own knowledge is now an orthodoxy in many colleges of education in English-speaking countries, and it has been adopted as the basis of educational reform in 29 other countries, including Japan, Taiwan, Mexico, Peru, Bolivia, and Brazil. In effect, Freire's culturally uninformed argument that the individual's construction of knowledge through critical reflection leads to emancipation and progress is the source of the double bind where emancipation requires

\footnotetext{
${ }^{10}$ John Dewey, Reconstruction in Philosophy (Boston: Beacon Press, 1948), p. xlii.

${ }^{11}$ John Dewey, The Quest for Certainty (New York: G.P. Putnam's Sons, 1960 edition), p. 79.

${ }^{12}$ As some readers may still hold to the uninformed idea that all indigenous cultures destroyed their environment, I suggest that they read: G. Bonfil Batalla, Mexico Profundo: Reclaiming a Civilization (Austin: University of Texas Press, 1996); Keith Basso, Wisdom Sits in Places: Landscape and Language Among the Western Apache (Albuquerque: University of New Mexico Press, 1996); Frederique Apffel Marglin (ed., with PRATEC), The Spirit of Regeneration: Andean Culture Confronting Western Notions of Development (London: Zed, 1998); and Jared Diamond, Collapse: How Societies Choose to Fail or Succeed (New York: Viking Penguin, 2005). These are only a few of the books to document the ecological wisdom of cultures that have combined careful observation of changes occurring within their environment, intergenerational knowledge of how to live in mutually supportive ways, and a sense of responsibility to the well-being of future generations. Their diverse approaches to renewing cultural practices that are ecologically sustainable require multiple forms of learning and renewal - strengths that do not fit Dewey's narrow scientifically based prescriptions.
} 
colonization by a Western Enlightenment ideal that has remained ignorant of both the differences in cultural knowledge systems and the impact of these knowledge systems on the environment.

Although Freire does not dismiss non-Western cultures as "savage," i.e., pagan and primitive, he shares with Dewey a Social-Darwinian orientation, within which he clearly states that humans evolve through three stages of development. In Education for Critical Consciousness, he explains the three stages in human evolution as "semi-intransitivity of consciousness," "transitivity of consciousness," and "critical transitivity of consciousness." The groups living in the interior of Brazil, according to Freire, exist at the level of semi-intransitive consciousness, and thus "cannot apprehend problems situated outside their sphere of biological necessity." In this animal stage of existence, "their interests center almost totally around survival, and they lack a sense of life on a more historical plane."13 The second stage of human evolution, "transitivity of consciousness," initially begins with a naïve phase where there is an over-simplification of problems, a nostalgia for the past, and a tendency to underestimate the potential of the common man. But as humans evolve further and reach the stage of critically transitive consciousness, they are capable of engaging in critical reflection, dialogue, and participating in democratic regimes. ${ }^{14}$ Freire identifies himself as well as his followers with the most evolved state of human development. Recently, a group of Third World activists reflected upon their experience of attempting to use Freire's approach to teaching literacy in cultures where they spoke the local languages - in India, Central Mexico, Peru, and Bolivia. They found that his pedagogy represented a Western way of thinking, and that the indigenous cultures that Freire identified as living at an animal stage of existence possessed a complex understanding of the local ecosystems that had enabled them to survive over thousands of years in the same bioregion. ${ }^{15}$

Given the view of the non-Western cultures held by both Dewey and Freire, it is not surprising that they failed to recognize that different cultures develop, in part, in response to the differences in the bioregions they inhabit. Their followers have also ignored the fundamental question of our era, which is the focus of Jared Diamond's book, Collapse: How Societies Choose to Fail or Succeed. Ironically, many of the cultures that Freire categorized as existing at an animal level of existence have not collapsed. Instead, as the Third World activists initially attempted to introduce critical thinking as part of the literacy program, they discovered that Freire's emphasis on emancipation from the knowledge of previous generations would undermine the complex knowledge of the sustaining characteristics of the local ecosystems - and would thereby lead to the culture's collapse.

\footnotetext{
${ }^{13}$ Paulo Freire, Education for Critical Consciousness (New York: Seabury Press, 1973), pp. 17-18.

${ }^{14}$ Ibid.

${ }^{15} \mathrm{C}$. A. Bowers and Frederique Apffel-Marglin (eds.), Rethinking Freire: Globalization and the Environmental Crisis (Mahwah, NJ: Lawrence Erlbaum, 2005).
} 


\section{Dewey and Freire Share Cultural Assumptions with Globalized Industrial Culture}

Our earlier discussion has identified a number of cultural assumptions that Dewey and Freire share with the Western elites who were responsible for the industrial culture that is undermining the local commons. While Dewey and Freire were critical of the undemocratic and exploitive nature of the West's industrial culture, they took for granted the need for continual experimentation without regard for the traditions that were being undermined. They also took for granted the assumption that change is linear and progressive when guided by critical reflection, along with an anthropocentric way of understanding human/nature relationships. In addition, they shared with the promoters of the industrial culture a way of regarding non-Western cultures as backward and thus in need of being rescued. They also identified themselves with liberalism without recognizing that a key component of liberal thinking is to view the expansion of free markets as the basis of social progress - and the expression of a natural law that humans can only ignore at their peril.

Readers may flinch at this criticism of Dewey and Freire. But they need to recognize that the experimental approach to knowledge advocated by Dewey is essential to the development of new technologies and to creating the infrastructure necessary for exploiting new markets. As Dewey put it, "the modern mine, factory, railway, steamship, telegraph, all the appliance and equipment of production and transportation express scientific knowledge." ${ }^{16}$ The task facing philosophers, as Dewey understood it, was to establish a new basis for determining the moral values that would make the benefits of the industrial culture available on a more equitable basis. This is a very different task than resisting the development of a global monoculture where, ironically, Dewey's method of scientific inquiry has been co-opted by technologists and business elites who have achieved greater efficiency in continually reconstructing daily experience through the introduction of new technologies and consumer products. It also needs to be emphasized that Freire's assumption that critical inquiry would always be used in the service of emancipation and in helping people achieve their highest potential as humans was equally naïve. What is generally not recognized by people who associate critical reflection with social justice is that critical reflection is also integral to instrumental problem solving that leads to new technologies, to plan wars of aggression, and to manipulate elections. And like Dewey's experimental inquiry, critical reflection has no built-in safeguards against ethnocentric thinking.

${ }^{16}$ John Dewey, 1948, op. cit., pp. 43-44. 


\title{
Why Dewey, Freire, and their Followers Continue to Ignore the Cultural and Environmental Commons as Sites of Resistance to Economic Globalization and Environmental Destruction
}

The emphasis of Dewey and Freire on achieving progress through the continual reconstruction and renaming of experience (i.e., the cultural patterns that are intergenerationally handed down) involves a double bind that they did not recognize. This may account for their criticism, as well as that of many of their followers, of what turns out to be the dominant characteristic of how the cultural and environmental commons are renewed: namely, the intergenerational knowledge of how to live less consumer-dependent and environmentally destructive lives. The intergenerational knowledge of the world's diverse cultural and environmental commons - narratives that in many instances encode the moral norms governing human/nature relationships, technologies adapted to the local environment, patterns of mutual support, mentoring in crafts and healing practices, and so forth - are also known as traditions. As explained earlier, both Dewey and Freire were against traditions, even as they re-enacted many of the traditions of their respective cultures in the act of speaking, writing, preparing a meal, overcoming illnesses, using money, and so forth.

The rejection of the "banking" approach to learning and the equally formulaic prescription that "speaking a true word changes the world" was Freire's way of dismissing all traditions as sources of oppression. Kirkpatrick Sale makes an observation in Rebels Against the Future that has particular relevance for understanding the implications of Freire's simplistic understanding of tradition-one which is also reproduced in the writings of his many followers. In writing about the difference between the Luddite's understanding of the relationship between the community and technology and the impact of the industrial approach to production on community, he notes that

\begin{abstract}
All that "community" implies — self-sufficiency, mutual aid, morality in the market place, stubborn tradition, regulation by custom, organic knowledge instead of mechanistic science - had to be steadily and systematically disrupted and displaced. All the practices that kept the individual from being a consumer had to be done away with so that the cogs and wheels of an unfettered machine called the "economy" could operate without interference, influenced merely by invisible hands and inevitable balances and all the rest of the benevolent freemarket system. ${ }^{17}$
\end{abstract}

Sale's observation about the form of individualism needed by the industrial culture - that is, the individual who has been liberated from the community's

\footnotetext{
${ }^{17}$ Kirkpatrick Sale, Rebels Against the Future: The Luddites and Their War on the Industrial Revolution (Reading, MA: Addison-Wesley, 1995), p. 38.
} 
knowledge and patterns of moral reciprocity that contributed to living more selfsufficient and less consumer-dependent lives - corresponds with Freire's ideal of the fully humanized individual who relies upon critical reflection to continually rename the world. Freire's ideal individual has abandoned the mentoring relationships, direct observation and embodied learning provided by the traditional community. But this also means sacrificing learning the skills suited to maintaining the built culture that fit the local environmental conditions, the patterns of mutual aid within the community, the arts and narratives that help to renew the culture's values and sense of identity, and the knowledge of acquiring the fiber and protein necessary to sustain life without degrading the environment.

In his last book, Mentoring the Mentor, Freire urges his followers to respect the cultural identity of the students and warns against the dangers of developing a paternalistic relationship with them. What appears as an awakening on Freire's part to the importance of maintaining the diversity of the world's cultures (which would be a potential first step to recognizing the connections between culture and biodiversity) turns out to be a ritualistic gesture dictated by the current stage of politically correct thinking. Later in the book, Freire demonstrates that he still does not understand that other cultures, such as the Quechua of the Peruvian Andes, the Inuit of the sub-artic North, and cultures based on Buddhist, Confucian, and Hindu cosmologies - to cite just a few-do not interpret freedom and development as leading to the total autonomy of the individual. It is also important to recognize that Freire's idea of mentoring was limited to emancipating students from the knowledge systems of their communities. He did not understand, for example, that mentors play an important role in passing on the knowledge, skills, and moral norms governing healing practices, artistic performances, human/nature relationships, agricultural practices, preparation of food and the social setting in which it is shared, and so forth. Rather, Freire addressed the potential pitfall in the teacher/student relationship and then ignored his own warning by proclaiming that the god-words of the West must be given primacy over all other cultural traditions. As he put it,

\begin{abstract}
The fundamental task of the teacher is a liberatory task. It is not to encourage the mentor's goal and aspirations and dreams to be reproduced in the mentees, the students, but to give rise to the possibility that the students become owners of their own history. This is how I understand the need that teachers have to transcend their merely instructive task and assume the ethical posture of a mentor who truly believes in the total autonomy, freedom, and development of those he or she mentors. (italics added) ${ }^{18}$
\end{abstract}

Again, it needs to be emphasized that if the person reading this statement is unaware of the profound differences in other cultural ways of knowing and is equally

\footnotetext{
${ }^{18}$ Paulo Freire (ed.), Mentoring the Mentor: A Critical Dialogue with Paulo Freire (New York: Peter Lang, 1997), p. 324.
} 
uninformed that the industrial culture relies upon many of the same assumptions that both Dewey and Freire took for granted, they are likely to consider Freire's statement as representing the highest ideals that all progressive reformers should strive to attain.

\section{How the Ideas of Dewey and Freire Contribute to Undermining What Remains of the World's Diverse Commons}

Part of the explanation of how Dewey, Freire, and their contemporary followers contribute to the further enclosure of the commons by the industrial culture has already been touched upon. A summary would include their long silence on the worsening state of natural systems, their emphasis on approaches to knowledge that are also the basis of technological innovation and of bringing more aspects of the cultural and environmental commons under the control of market forces, and their Social Darwinian thinking that justified the imposition of the high-status approaches to knowledge on other cultures - all in the name of democracy and freedom.

Even though Dewey argued that experimental inquiry would free humankind from the constraints of the spectator approach to knowledge as well as superstitions, he could not escape conforming to the cultural practices and ways of thinking of his era. His argument for the use of the method of intelligence was based on a false dichotomy that prevented him from examining the taken-for-granted cultural patterns, assumptions, and silences that are not experienced as part of problematic situations. But before examining more closely why his approach to knowledge could not take account of one of the more distinctive characteristics of the commons, it is necessary to identify an aspect of his thinking essential to the renewal of the cultural commons - and which, by extension, would help to reduce the adverse impact of industrial/cultural practices on the environmental commons.

One of the chief characteristics of the cultural and environmental commons is that access and use are not restricted by private or corporate ownership (though they may be restricted by the status system and other cultural norms). In today's world, access to water in urban and most rural towns is provided by municipal water systems. This is still, in most places, under the local control of democratic decisionmaking, as is access to water from nearby streams or even private wells. Democratic decision-making is part of the process of deciding what is to remain part of the commons, and what is to be governed by the laws and greed of the marketplace. A case can be made that even though the monetizing of the cultural commons has been carried to an extreme in the United States and other Western countries, there are still aspects of the cultural commons that are governed by local decision-making. While Dewey emphasized that the experimental method of inquiry was best suited to resolving problematic situations, he also emphasized that the widest possible communication between members of the community would ensure the fullest understanding of the problematic situation — and thus would lead to solutions that 
best fit the community's expectations. In effect, his emphasis on participatory decision-making (as long as all the participants did not fall back on other sources of moral authority and approaches to knowledge) is in line with how many cultures have protected the commons over the past centuries. While this aspect of Dewey's thinking supports a core feature that is essential but not always successful in sustaining the commons, his reductionist way of understanding the nature of traditions is the source of a double bind in his thinking. Unfortunately, environmentalists who are beginning to look to Dewey's ideas as the foundation for addressing environmental issues fail to recognize how other aspects of his thinking support the Western project of neoliberal globalization.

Dewey should not be criticized because he did not understand how the metaphorical nature of language reproduces earlier culturally based misconceptions (though Nietzsche had written about this in the 1880s). It is also debatable whether he should be judged for ignoring the writings of Edward Sapir on how different languages reproduce different cultural ways of knowing (Sapir's paper on "The Status of Linguistic as a Science" was presented in 1929). But that his understanding of tradition should be criticized should be beyond debate. In addition to his support of scientifically based technologies that have enclosed many aspects of the cultural and environmental commons, Dewey's arguments about the non-intelligent nature of traditions places nearly his entire social justice agenda in opposition to sustaining what remains of the world's diverse cultural and environmental commons.

It will be useful here to give a more extended account of how Dewey understood the nature of "tradition," a notion that still connotes for many progressives the meanings given by the Enlightenment that represent traditions as maintaining the status quo, special privileges, and backwardness. Needless to say, certain traditions do serve such roles. But by totalizing all tradition as the antagonist of experimental inquiry, Dewey failed to both understand the full meaning of tradition and recognize that his anti-tradition way of thinking is itself a longstanding tradition in the West.

Looking more closely, it appears that Dewey relied upon an implicit meaning of tradition in order to account for the non-problematic aspects of daily experience. $\mathrm{He}$ also acknowledges that past ideas and practices which are part of the experience being reconstructed may be incorporated into the formation of the hypothesis that is to be tested in action. But he fails to recognize that most of daily experience-writing from left to write (in English-speaking cultures), using a subject-verb-object pattern of writing and speaking, re-enacting the cultural message system of non-verbal communication, making assumptions about the importance of separation of church and state, valuing literacy, promoting the traditions of thinking that underlie Western science and technology - including the myth that technology is simply a neutral tool-and so on, are themselves examples of traditions. If he had given attention to the role of traditions in daily life, as well as the traditions of other cultures, he would have recognized that some traditions are sources of empowerment, 
some change too slowly, while other are displaced before we realize how important they were - such as the right to privacy, and now the undermining of the separation of church and state. He would have also recognized that some traditions were unjust from the outset (indeed he writes about the unjust nature of capitalism in Liberalism and Social Action); and he might have come to the insight that some people make the opposite mistake to the one he makes: While they assume wrongly that traditions do not change, he assumes wrongly that everything is in a state of change. Because he brings the existence of traditions in through the back door, so to speak, where their complex nature does not have to be recognized, he is unable to ask the most important question raised by the industrial culture he celebrates: namely, what traditions need to be conserved and renewed because they contribute to the commons as sites of resistance to the industrial culture that reduces both nature and people either to an exploitable resource or to an exploitable market?

Instead of being a careful observer of the cultural patterns enacted in daily experience, Dewey chose instead to treat both experimental inquiry and traditions as theoretical abstractions in his writings. Thus, in Democracy and Education, he equates traditions with habits and almost gets it right when he states that habits involve the "formation of intellectual and emotional disposition as well as in ease, economy, and efficiency of action." 19 He then goes on to stake out a position that he will restate over and over again:

\begin{abstract}
Habits reduce themselves to routine ways of acting, or degenerate into ways of action to which we are enslaved just in the degree in which intelligence is disconnected from them. Routine habits are unthinking habits; "bad" habits are habits so severed from reason that they are opposed to the conclusions of conscious deliberation and decision. As we have seen, the acquiring of habits is due to an original plasticity of our natures; to our ability to vary responses till we find an appropriate and efficient way of acting. Routine habits, and habits that possess us instead of our possessing them, are habits that put an end to plasticity. $^{20}$
\end{abstract}

In Reconstruction in Philosophy, traditions are explained as man's efforts to preserve past experiences. Rather than use specific traditions such as the traditions of habeas corpus, trial by a jury of peers, the presumption of innocence until proven guilty, Dewey makes the sweeping and culturally uninformed generalization that traditions are only a source of memory - and that "the primary life of memory is emotional rather than intellectual and practical." 21 In The Quest for Certainty, he goes further in setting up a false dichotomy between tradition and knowledge when he writes that "knowledge which is merely a reduplication in ideas of what exists

\footnotetext{
${ }^{19}$ John Dewey, 1916, op. cit., p. 57.

${ }^{20}$ Ibid., p. 58.

${ }^{21}$ John Dewey, 1948, op. cit., p. 2.
} 
already in the world merely affords us the satisfaction of a photograph, but that is all." 22

Dewey represents intelligence (experimental inquiry) as the opposite of tradition (habit) just as Freire represents critical inquiry as the opposite of passing on intergenerational knowledge. What is important to keep in mind in assessing the relevance of these two theorists for helping to sustain the commons is that neither one took a truly critical account of the traditions within their own cultures, or the traditions of other cultures. Dewey, the celebrated champion of democracy and of making experience an integral part of experimental inquiry, ends up promoting another set of abstractions that provide legitimacy for the neoliberal/corporate interest by conditioning the public to equate constant technological change with progress.

Furthermore, the influence of Dewey and Freire on the current generation of their followers can also be seen in how differences in the knowledge systems of other cultures are totally ignored in their prescriptions for educational reform. Peter McLaren, for example, responded to my efforts to explain the danger of ignoring how indigenous cultures such as the Quechua of the Peruvian Andes were sustaining the commons by claiming that I was re-introducing the notion of the "noble savage." ${ }^{23}$ Another influential follower of the idea that education should foster constant change (or as it is now known in the field, "transformative learning") is Henry Giroux. Writing in EDucate!, a journal published in Pakistan, he recommended that teachers should become transformative intellectuals by developing "a discourse that unites the language of critique with the language of possibility, so that social educators can recognize that they can make changes." ${ }^{24}$ Edmund O'Sullivan's Transformative Learning: Educational Vision for the 21st Century, is yet another example of how the idea of change in the Deweyian and Freirean tradition of thinking continues to be central to the current discourse of supposedly radical social justice educational theorists. ${ }^{25}$ It needs to be reiterated here that the industrial culture, in its never-ending need to create new markets by introducing new technologies as well as commoditizing more aspects of the commons, is now the greatest transformative force in the world. And like the followers of Dewey and Freire, the neoliberal ideologues of economic globalization are silent about conserving traditions in the areas of civil liberties, intergenerational knowledge of how to live less consumerdependent lives, and the cultural/linguistic diversity so essential to conserving biodiversity.

\footnotetext{
${ }^{22}$ John Dewey, 1916, op. cit., p. 137.

${ }^{23}$ Peter McLaren and Donna Houston, "The Nature of Amnesia: A Response to C. A. (Chet) Bowers," Educational Studies, 37, 2, 2005, pp. 196-205.

${ }^{24}$ Henry Giroux, "Teachers as Transformatory Intellectuals," EDucate!, 1, 2, July-Sept. 2002, pp. $46-49$.

${ }^{25}$ Edmund O'Sullivan, Transformative Learning: Educational Vision for the $21^{\text {st }}$ Century (London: Zed Books, 1999).
} 


\section{Ways of Knowing Essential to Revitalizing the Commons as Sites of Resistance to Globalization and Environmental Degradation}

Rather than attempting to address the problem of globalization and the ecological crisis by relying upon the theories of Dewey and Freire, we should retain those aspects of their theories that were part of the Western tradition of thought before the non-historically informed followers of Dewey and Freire assumed that they were originators of these ideas. Critical reflection, which can be traced back at least to Socrates, needs to be practiced, but within an entirely different set of priorities. That is, critical reflection is essential to making explicit those traditions and new political, economic, and technological developments that undermine the cultural and environmental commons. For example, critical reflection is essential to clarifying what is wrong with E. O. Wilson's argument for evolution becoming the new "master" narrative that all cultures should adopt, and that scientists should make the decision about which cultural practices and values should be retained. ${ }^{26}$ The current efforts to reverse the gains in the labor movement, to genetically alter seeds so that they are sterile - thus forcing the farmer to purchase seeds for the next year's planting - should also be subjected to critical reflection. In terms of these examples, critical reflection helps to bring to attention what is being overturned - that is, the traditions that need to be renewed and carried forward.

Democratic decision-making as well as dialogue were understood and practiced long before Dewey and Freire incorporated them into their theories. And they need to be retained, especially since they are essential to local decision-making about how to sustain the commons. However, the idea that each individual (Freire) and each generation (Dewey) should reconstruct the problematic aspects of community by relying solely upon the modes of thinking that are also the sources of scientificl technological innovation and the growing hegemony of market forces must now be questioned. Similarly, we should question the idea that reading the various proposals for an environmental ethic, such as Aldo Leopold's "Land Ethic," or the collection of essays in Environmental Ethics (edited by Andrew Light and Holmes Rolston III, 2003) will lead in themselves to the actual daily practice of an environmental ethic. Reading may lead to energetic discussions in the classroom, but it may be less effective in terms of living in ways which have a smaller ecological foot print, such as learning to prepare a meal from wholesome ingredients, to repair a roof, to play an instrument, to return work and thus help a neighbor, to develop a talent under the guidance of a mentor, to plant a garden, and so forth. What is often overlooked in our reading-oriented culture, which is now being transformed by computer-mediated literacy, is that the daily enactment of the knowledge and practices that sustain the commons represents the practice of an environmental ethic. Moreover, if theorists and critics of globalization are to avoid the double binds inherent in the ideas of Dewey and Freire, they will need to acquire a more complex understanding of the nature of tradition - their own as well as those of other cultures.

\footnotetext{
${ }^{26}$ E. O. Wilson, Consilience: The Unity of Knowledge (New York: Alfred A. Knopf, 1998), pp. 264-265.
} 
The cultural commons are not a theoretical abstraction. Rather, their many dimensions exist in the knowledge, embodied experiences, practices, and patterns of moral reciprocity that characterize those aspects of daily life that have not been coopted by the market. The commons vary from culture to culture, but a key feature of all the world's diverse commons is that they are not created anew by each generation or by individuals who rely exclusively on critical reflection. "Tradition" is the best word for describing the varied characteristic of the commons - with some of the traditions being sources of injustice and environmental degradation, while others contribute to community self-sufficiency and are sources of resistance to globalization (sometimes within the same culture). Instead of continuing to be captives of the Enlightenment thinkers' narrow and culturally uninformed understanding of tradition, which has been passed down over generations and reproduced in the thinking of many current progressive theorists, there is a need to learn about the traditions carried on within what remains of the local commons - traditions that both include the language of moral reciprocity and sustain the memory of the civil institutions and practices that are safeguards against the forces of fascism and economic exploitation that are now again on the rise.

The failure of progressive theorists such as Dewey and Freire, as well as university and public school teachers, to examine the complex nature of traditions and to help students learn to assess traditions in terms of whether they contribute to morally coherent and ecologically sustainable commons has had at least two undesirable consequences. One is the silence on the part of progressive theorists about the importance of determining which aspects of the cultural and environmental commons need to be conserved and renewed. The other is the widespread misunderstanding of the complex nature of tradition that now underlies the thinking of fundamentalists and other extremists, who hold that traditions should not be changed - and that the present must be made to fit their interpretations of the past (even while they support the expansion of economic globalization). The challenge will be to realign our political language in ways that take account of what sustains the commons as sites of resistance to the further expansion of market forces, and thus to escape the linguistic hegemony that Dewey, Freire, and their followers accepted so readily. 